F. Ouvrier-Buffet et al., Linear and nonlinear resonant ultrasonic techniques applied to assess delayed ettringite formation on concrete samples, Construction and Building Materials (2021) - https://doi.org/10.1016/j.conbuildmat.2020.121545

\title{
Linear and nonlinear resonant ultrasonic techniques applied to assess delayed ettringite formation on concrete samples
}

Author names and affiliations:

Florian OUVRIER-BUFFET ${ }^{1,2}$, Jesús N. EIRAS ${ }^{2}$, Vincent GARNIER ${ }^{2}$, Cédric PAYAN ${ }^{2}$, Narintsoa

RANAIVOMANANA ${ }^{3}$, Benoît DURVILLE ${ }^{1}$, Christophe MARQUIE $^{1}$

${ }^{1}$ IRSN/PSN-RES/SEREX (Cadarache -FRANCE)

Institut de Radioprotection et de Sûreté Nucléaire (IRSN) - Cadarache BP3 - 13115 Saint-Paul-Lez-Durance - France

${ }^{2}$ Aix Marseille Univ, CNRS, CentraleMarseille, LMA UMR 7031, Marseille, France

${ }^{3}$ LMDC EA3027 UPS/INSA (Toulouse -FRANCE)

Laboratoire Matériaux et Durabilité des Constructions de Toulouse - 135 Avenue de Rangueil - 31077 Toulouse Cedex 4 - France

Corresponding Author:

Florian OUVRIER-BUFFET, E-mail address: florian.ouvrier.buffet@gmail.com 
F. Ouvrier-Buffet et al., Linear and nonlinear resonant ultrasonic techniques applied to assess delayed ettringite formation on concrete samples, Construction and Building Materials (2021) - https://doi.org/10.1016/j.conbuildmat.2020.121545

Abstract:

This study investigates the application of different ultrasonic Non-Destructive tests to assess Delayed Ettringite Formation, in concrete samples exhibiting low kinetic expansions (and up to 0.21\%). Linear and nonlinear Resonant Ultrasonic Spectroscopy and Acoustic Emission tests were used. Scanning Electron Microscopy and optical microscopy observations were conducted at the end of the monitoring tests. The results showed a slight increase of the dynamic modulus and Quality factor while nonlinear hysteretic parameters remained constant over the test duration. Acoustic Emission tests attested the occurrence of events. However, the microscopic observations did not reveal meaningful differences in microcracking extent between the samples.

Keywords: Nondestructive Testing, Nonlinear acoustics, Ultrasonic, Concrete, Swelling pathologies, Delayed Ettringite Formation 
F. Ouvrier-Buffet et al., Linear and nonlinear resonant ultrasonic techniques applied to assess delayed ettringite formation on concrete samples, Construction and Building Materials (2021) - https://doi.org/10.1016/j.conbuildmat.2020.121545

\section{Introduction}

Delayed Ettringite Formation (DEF) is a swelling pathology of concrete that can take place when the curing temperature remains sufficient time above $65^{\circ} \mathrm{C}$ at early-ages. At such temperatures, the formation of ettringite, naturally present in hydrated Portland cement cured at normal temperatures, remains dissolved in the interstitial solution due to its thermochemical properties. Subsequent crystallization of ettringite (secondary form) in hardened concrete after cooling may then produce internal pressures leading to expansion, possibly causing microcracking damage, and so to impaired mechanical and durability performance [1]. Otherwise, originally formed primary ettringite in hardened concrete may be dissolved after exposure to elevated temperatures to subsequently recrystallize upon the cooling down. The mechanisms leading to deleterious DEF are still not fully understood. However, the likelihood of DEF to cause deleterious expansions on a concrete structure is dependent on among other factors, the curing temperature history, the chemical composition of the cement, and the exposure to moisture [2,3]. DEF has been observed on massive concrete structures [4,5] wherein the temperatures in the core may be quite elevated and on steam-cured precast concrete elements [6].

Recently, the French Nuclear Safety Authority (ASN) warned that structural concrete elements of the Chooz nuclear power plant could be affected by DEF [7]. Indeed, massive concrete elements in nuclear power plants may be prone to develop DEF. The study of the susceptibility of concrete to develop DEF is therefore important to ensure the durability of the concerned structures. Commonly, the DEF durability performance tests in cement-based materials lie on the standard measurements of the relative expansion length [3,8]. However, the sole measurement of sample expansion is not sufficient to deem the susceptibility of a concrete mix against DEF. In many instances, the measurement of dynamic modulus has complemented expansion measurements. Still, the need for new physical parameters that provide further information on the mechanical performance of concrete upon DEF has been claimed in several study reviews [9-11]. In recent years, the evaluation of the nonlinear mechanical behavior through resonant experiments has been satisfactorily applied to assess different durability distresses in concrete, such as alkali-silica reaction [12-14] freezing-thawing damage [15-17], thermal damage [18,19], and carbonation [20,21]. The evaluation of the nonlinear properties of concrete upon the development of DEF has seldom been studied. The study realized by Rashidi et al. [22] has shown promise for assessing the DEF on mortar samples. In this study, we evaluate the susceptibility of a concrete type, with constituents commonly used in nuclear facilities, to develop DEF through the evaluation of standard nondestructive means: relative expansion and mass changes and dynamic modulus of elasticity. We consider also the Quality factor (inverse attenuation) and the nonlinear hysteretic parameters. The tests are realized on three concrete samples produced with identic concrete composition. Each sample, however, was subjected to different curing conditions to either promote or inhibit the DEF and so produce three different extents of expansion. Furthermore, one acoustic emission sensor was attached to every sample to track the acoustical events generated because of the microstructural modifications. Besides, two different resonant acoustic configurations were used to monitor the evolution of the mechanical properties: dynamic modulus, quality factor (inverse attenuation), nonlinear hysteretic parameter, and nonlinear dissipation; this latter two are detailed in section 2. The complete set of measurements were performed during 150 days after completing 28 days of curing. Finally, Scanning Electron Microscopy (SEM) and optical microscopy observations under normal- and UV-light were conducted at the end of the monitoring to assist in the interpretation of the nondestructive inspection results. The remainder of this work is structured as follows. In section 2 we provide background information on nonlinear resonance testing, section 3 describes the test samples, the heat-treatment, and the inspection techniques. Section 4 summarizes the results. Finally, in section 5 we discuss the experimental results and draw the conclusions of this study.

\section{Background information}

The constitutive mechanical properties of concrete are nonlinear and hysteretic. For a one-dimensional case, the nonlinear modulus can be described as [23]

$M(\varepsilon, \dot{\varepsilon}, \Delta \varepsilon)=M_{0}\left(1-\beta \varepsilon-\delta \varepsilon^{2}-\cdots-\gamma(\varepsilon, \dot{\varepsilon}, \Delta \varepsilon)\right)$

where $M_{0}$ is the linear elastic modulus, $\varepsilon$ is the strain, $\dot{\varepsilon}$ is the strain rate, and $\Delta \varepsilon$ is the strain amplitude. The coefficients $\beta$ and $\delta$ are the classical nonlinear (atomic) parameters, and $\gamma(\varepsilon, \dot{\varepsilon}, \Delta \varepsilon)$ is a function that enables the description of the mechanical hysteresis. In resonant frequency measurements, the hysteretic behavior leads to a linear decrease in resonant frequency with increasing strain amplitude excitation as

$\frac{f(\Delta \epsilon)-f_{0}}{f_{0}}=-\alpha_{f} \cdot \Delta \epsilon$

and, to nonlinear energy losses as

$\frac{1}{Q(\Delta \varepsilon)}-\frac{1}{Q_{0}}=\alpha_{Q} \cdot \Delta \varepsilon$ 
F. Ouvrier-Buffet et al., Linear and nonlinear resonant ultrasonic techniques applied to assess delayed ettringite formation on concrete samples, Construction and Building Materials (2021) - https://doi.org/10.1016/j.conbuildmat.2020.121545

wherein $f_{o}$ and $Q_{o}$ are the resonant frequency and Quality factor obtained at linear strain regime; usually well below $10^{-7}[24] . Q(\Delta \varepsilon)$ is the quality factor for the amplitude level $\Delta \varepsilon$.

The parameters $\alpha_{f}$ and $\alpha_{Q}$ are referred to as the nonlinear hysteretic parameters. Since the mechanical hysteretic behavior in concrete can be ascribed to increased microcracking damage extent, any absolute increase of the hysteretic parameters can be related to internal microcracking damage. The technique referred to as Nonlinear Resonance Ultrasound Spectroscopy (NRUS) [23] is commonly used to evaluate these parameters. The principle of the test is based on repeating resonance acoustic tests at increasing amplitude levels.

\section{Material and methods}

\subsection{Sample preparation, curing, and accelerated aging}

Three prismatic concrete specimens measuring $7 \times 7 \times 28 \mathrm{~cm}^{3}$ were produced. Table 1 summarizes the concrete batch composition. The water to cement ratio was set to 0.48 . Cement was enriched with alkali content by adding sodium hydroxide $(\mathrm{NaOH})$ to the mixing water for lowering the destabilization temperature of primary ettringite at an early age [25]. It should be noted that a high alkaline content may lead to the development of Alkali-Silica Reaction (ASR). From previous experiences, the concentration total alkali content of $5.1 \mathrm{~kg} / \mathrm{m}^{3}$ was found a satisfactory compromise [26].

Table 1: Concrete mixture design

\begin{tabular}{|l|l|r|}
\hline Constituents & Designation & $\mathbf{k g} / \mathbf{m}^{\mathbf{3}}$ \\
\hline Cement & CEM I 52,5 R CE CP2 NF, Lafarge (Le Teil) & 410 \\
\hline Fine aggregate & Palvadeau 0/0.315 mm & 94 \\
\hline Fine aggregate & Palvadeau 0.315/1 mm & 174 \\
\hline Fine aggregate & Palvadeau 1/4 mm & 184 \\
\hline Fine aggregate & Palvadeau 2/4 mm & 196 \\
\hline Coarse aggregate & Palvadeau 4/8 mm & 188 \\
\hline Coarse aggregate & Palvadeau 8/12.5 mm & 878 \\
\hline Water & Demineralized water & 197 \\
\hline Total alkali content & $\mathrm{Na}_{2} \mathrm{O}_{\mathrm{eq}}$ & 5.1 \\
\hline
\end{tabular}

Table 2 summarizes the sample designations and curing conditions. The unalike curing conditions make it possible to attain different expansion extents in every specimen. The S1 specimen (control) was cured for 28 days at $20^{\circ} \mathrm{C}$ and relative humidity $>95 \%$. In contrast, directly after pouring the specimens S2 and S3 were introduced in a climatic chamber and subjected to a heat-treatment to promote the development of DEF. The heat-treatment protocol is shown in Figure 1. The curing temperature reached a maximum of $80^{\circ} \mathrm{C}$ in 33 hours and decreased gradually to $20^{\circ} \mathrm{C}$ in 14 days with relative humidity $\geq 95 \%$. The heat-treatment curve reproduced the expected thermal profile in the core of a massive concrete piece, as determined by numerical simulations in the Reference [27]. The S2 and S3 specimens were subsequently kept 14 additional days at $20^{\circ} \mathrm{C}$. At this stage, to either promote or attenuate the DEF, the specimens were immersed in different solutions at $38^{\circ} \mathrm{C}$. A temperature of $38^{\circ} \mathrm{C}$ is considered to be low enough to not dissolve the ettringite and overall accelerate the aging of the samples [28]. A $0.6 \mathrm{~mol} / \mathrm{l} \mathrm{LiOH}$ solution was used to slow down the development of DEF on specimen S2. The control specimen S1 was likewise immersed in a LiOH solution. Finally, the specimen S3 was immersed in water and so, it is expected to attain the greater expansion herein. In all three instances, the volume of the solutions was kept to twice the volume of the concrete specimens, over the test duration. The evolution of the physical changes of the specimens was monitored since the immersion. 
F. Ouvrier-Buffet et al., Linear and nonlinear resonant ultrasonic techniques applied to assess delayed ettringite formation on concrete samples, Construction and Building Materials (2021) - https://doi.org/10.1016/j.conbuildmat.2020.121545

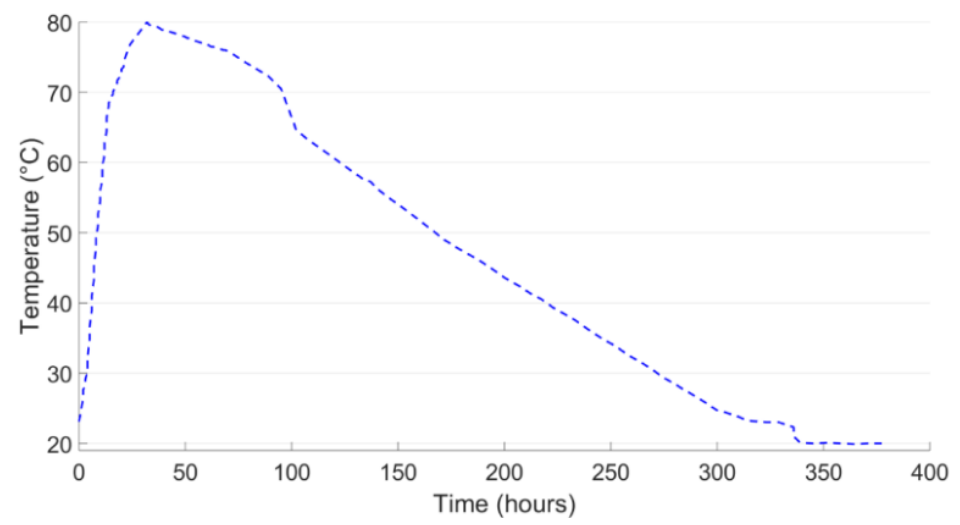

Figure 1: Heat-treatment protocol; temperature profile measured on concrete specimens S2 and S3.

Table 2: Designation of the test specimens, aging conditions, and expected expansion.

\begin{tabular}{|c|c|l|l|}
\hline Specimens & Heat-treatment & \multicolumn{1}{|c|}{ Accelerated aging conditions } & \multicolumn{1}{|c|}{ Expected expansion } \\
\hline S1 & No & Soaked in $\mathrm{LiOH}$ solution $(0.6 \mathrm{~mol} / \mathrm{l})$ at $38^{\circ} \mathrm{C}$ & No DEF (control) \\
\hline S2 & Yes & Soaked in LiOH solution $(0.6 \mathrm{~mol} / \mathrm{l})$ at $38^{\circ} \mathrm{C}$ & Weak DEF \\
\hline S3 & Yes & Soaked in demineralized water at $38^{\circ} \mathrm{C}$ & Moderate-DEF \\
\hline
\end{tabular}

\subsection{Inspection techniques}

\subsubsection{Relative length and mass changes}

Two stainless steel gauges studs that were cast in the specimen ends allowed the measurement of the relative changes of sample length. The expansion was ascertained with a length comparator which allowed a length change precision $<0.01 \%$. A weighing scale with a $1 \mathrm{~g}$ readability was used for the sample mass measurements.

\subsubsection{Acoustic Emission (AE)}

$\mathrm{AE}$ is a passive monitoring technique frequently used to record the ultrasonic waves (called hits) generated by the transient elastic energy releases emitted by the generation of cracking damage in materials [29]. Herein, one AE transducer was attached to every sample for sensing the acoustic events produced during the accelerated aging. The transducers $(\mathrm{R} 15 \alpha$, resonant frequency $150 \mathrm{kHz})$ were attached with silicone adhesive and a leaf spring helped to maintain a constant force and prevent that the transducers be detached during the monitoring (150 days). An acquisition system (Mistras-PCI8) equipped with a bandpass filter $(100-400 \mathrm{kHz})$ and $40 \mathrm{~dB}$ preamplifiers were used for the measurements. Different Rise-time Amplitude (R-A) and Duration-Amplitude (D-A) type filters were applied to the acquired signals. These filters are commonly applied because they retain transient-like events which can likely be attributed to cracking damage [30]. Table 3 summarizes the rejection limits set on this study for the D-A and R-A filters. The configuration of these filters was inspired by the work of Abdelrahman et al. on alkali-silica reaction [31]. The AE monitoring was only suspended when the samples were removed from their containers for other measurements.

Table 3: Rejection limits for $D-A$ and $R$-A filters

\begin{tabular}{|l|l|l|l|}
\hline \multicolumn{2}{|c|}{ D-A } & \multicolumn{2}{c|}{ R-A } \\
\hline Duration $(\mu \mathrm{s})$ & Amplitude $(\mathrm{dB})$ & Rise time $(\mu \mathrm{s})$ & Amplitude $(\mathrm{dB})$ \\
\hline$\leq 35$ & $>50$ & $>125$ & $\leq 50$ \\
\hline $35-70$ & $>55$ & $>200$ & $51-60$ \\
\hline $70-110$ & $>70$ & $>300$ & $61-70$ \\
\hline$>400$ & $\leq 45$ & $>400$ & $71-100$ \\
\hline$>500$ & $46-50$ & & \\
\hline$>600$ & $51-53$ & & \\
\hline
\end{tabular}




\subsubsection{Linear and Nonlinear Resonant Ultrasonic Spectroscopy (RUS)}

Figure 2a shows the experimental setup used for resonant ultrasound spectroscopy. A software-driven generator (model PXI) was used to generate a frequency sweep between 2.5 and $10 \mathrm{kHz}$ to promote the first bending and first torsional modes of vibration. These modes were then identified after peak-peaking the local maxima in the frequency domain. Two ultrasonic transducers were used for emitting and receiving the resonant vibration. The dynamic modulus of elasticity and Poisson's ratio were derived from the formulae provided in the standard ASTM C215 [32]. The Quality factor $Q$ was obtained for the first longitudinal frequency mode peak and its corresponding bandwidth at $3 \mathrm{~dB}$ in the resonant spectra.

Figure $2 \mathrm{~b}$ shows the NRUS experimental setup used for the measurement of the nonlinear hysteretic parameters. Frequency sweeps around the longitudinal resonant frequency mode were applied at increasing amplitude levels with the aid of an electromechanical shaker (Brüel and Kjaer, Type 4809) which was attached to one sample end. A laser vibrometer (Polytec OFV-505) sensed the resonant vibration at the opposite sample end. On the one hand, the hysteretic parameter $\alpha_{f}$ was calculated from Equations 2. On the other hand, the nolinear energy loss parameter $\alpha_{Q}$ was obtained as [33]

$\frac{1}{Q(\Delta \varepsilon)}-\frac{1}{Q_{0}}=\frac{1}{Q_{0}}\left(\frac{V \cdot \Delta \varepsilon_{0}}{V_{0} \cdot \Delta \varepsilon}-1\right)$

since for continuisly driven systems, $Q(\Delta \varepsilon)$ cannot be calculated directly from the bandwith at $-3 \mathrm{~dB}$ due to the nonlinear distortion of the resonance peak [33]. $V_{0}$ is the voltage applied to the shaker to determine $Q_{0}$ and $\Delta \varepsilon_{0}$ the resulting strain amplitude. $V$ is the applied voltage leading to the strain amplitude $\Delta \varepsilon$. The relationship voltage-force delivered by the shaker over the frequency range was constant because it operated well below its resonance frequency. The strain amplitude was derived from the measured velocity (we used a laser vibrometer) using a calibrated Finite Element Model of the sample, akin to the approach described in [34].

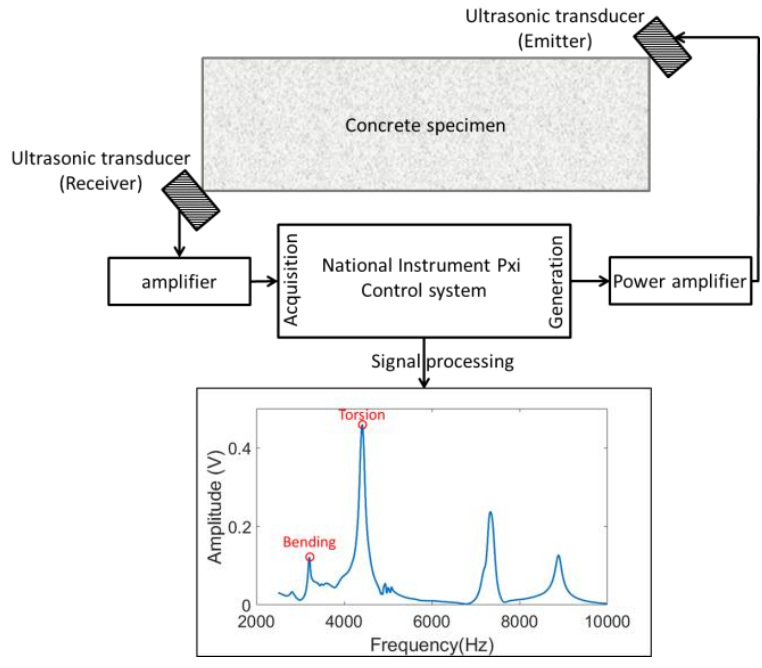

a)

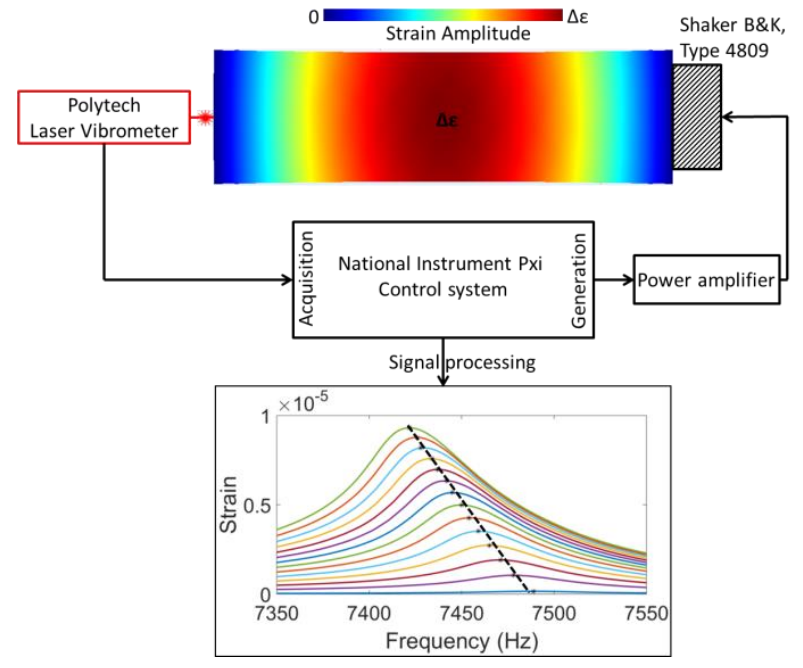

b)

Figure 2: Experimental setup used for a) RUS experiments and b) NRUS experiments

\subsubsection{Microscopy}

Two microscopy techniques were used. Samples taken from specimens S1 and S3 were cut at appropriate dimensions, oven-dried, and impregnated with a very fluid epoxy resin containing an ultraviolet fluorescent agent under vacuum. Microscopical examinations were carried out with optical microscopes under normal-light (magnification from 8x to 40x) and UV-light (magnification from x80 to $\mathrm{x} 400$ ).

A Scanning Electron Microscopy (SEM) apparatus equipped with an Energy Dispersive X-ray Spectroscopy detector was used on another set of samples taken also from specimens S1 and S3. Sample preparation for SEM examinations consisted of splitting the sample under tension to provide a regular breaking surface. This preparation technique 
F. Ouvrier-Buffet et al., Linear and nonlinear resonant ultrasonic techniques applied to assess delayed ettringite formation on concrete samples, Construction and Building Materials (2021) - https://doi.org/10.1016/j.conbuildmat.2020.121545

avoids further crack formation, The samples were dried by sublimation in a vacuum freeze drier and then carbon coated under vacuum.

\section{Results and discussion}

Figures $3 \mathrm{a}$ and $3 \mathrm{~b}$ show the relative length and mass changes obtained for the three specimens. The results show that the different curing and aging conditions produced unalike extents of expansion. Usually, concrete samples are considered to be affected by DEF when the expansion is higher than $0.04 \%$ [35]. After 150 days of accelerated aging, these were $0.02 \%$ for the reference S1 specimen, and $0.06 \%$ and $0.21 \%$ for the heat-treated (S2 and S3) specimens. The heat-treated specimens S2 and S3 expanded monotonically with average expansion kinetics of $0.0004 \%$ and $0.0014 \%$ per day. In contrast, the S1 specimen attained a relative expansion of $0.02 \%$ after 20 days and it remained constant from this day onwards. The initial expansion of the S1 specimen can be ascribed to moisture absorption. Indeed, a meaningful increase in specimen mass took place in all specimens. This increase in specimen mass was considerably higher for specimens S2 and S3. The latter may be the consequence of the heat-treatment at early-ages that hampered the normal cement hydration, hence resulting in relatively higher porosity in these specimens. From the $20^{\text {th }}$ day onwards, the mass increased at a slower rate because of further moisture absorption in all cases.

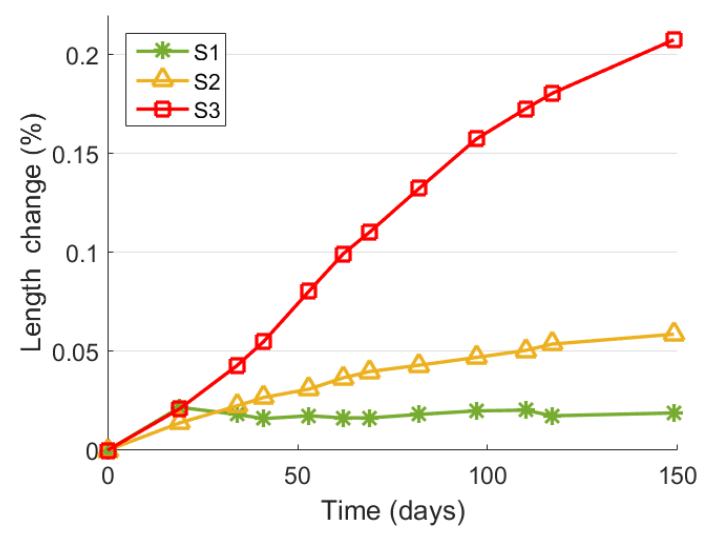

a)

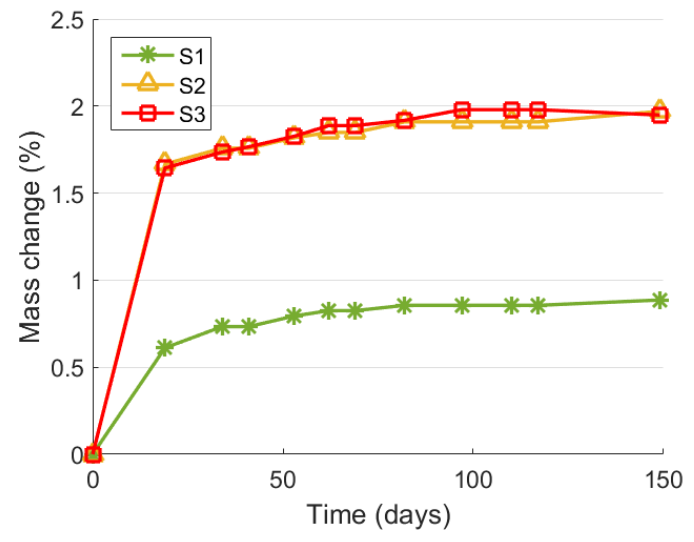

b)

Figure 2: Relative changes of a) length, and b) mass.

Figure 4 shows the cumulative number of AE hits obtained for the three specimens. The AE hit counting started the $10^{\text {th }}$ day since a substantial number of hits (unlikely attributable to DEF) were identified during the first days. These were attributed to the initial specimens' conditioning (i.e moisture absorption, moisture-induced swelling). The AE results showed that heat-treated specimens exhibited higher activity than the reference one and attested that different expansive behavior took place. In all instances, the cumulative AE hit curves exhibit sharp "jumps". Discounting these sudden jumps, the results show that the number of AE hits per day (slope) was on average 6, 18, and 31 hits/day for $\mathrm{S} 1, \mathrm{~S} 2$ and S3 respectively. This latter result was in good agreement with the measured length changes. However, more specimens have to be studied to confirm these observations. In any event, the AE activity was deemed to be low if compared to other studies. See for instance the reference [31] wherein the most reactive sample accrued $~ 120$ times more hits than their non-reactive reference for an expansion of $0.04 \%$. Still, a comparison between different studies is difficult since the AE results are strongly dependent on filter and test configuration.

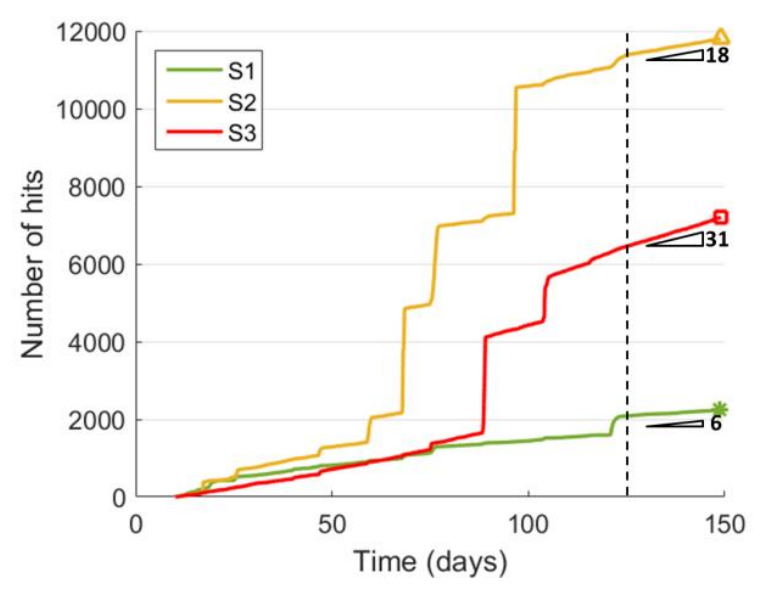


F. Ouvrier-Buffet et al., Linear and nonlinear resonant ultrasonic techniques applied to assess delayed ettringite formation on concrete samples, Construction and Building Materials (2021) - https://doi.org/10.1016/j.conbuildmat.2020.121545

Figure 3 : AE activity over time (cumulative hits). The number of recorded hits per day (slopes)

between day 125 and 149 are also appended.

The variations of the dynamic elastic modulus and $Q$ are shown in Figures $5 \mathrm{a}$ and $5 \mathrm{~b}$. The initial value of the $\mathrm{S} 1$ specimen was $\sim 44 \mathrm{GPa}$ while for the heat-treated specimens ( 22 and S3) was $\sim 42 \mathrm{GPa}$. This difference can be also attributed to the heat-treatment. This observation further supports the conclusion that the heat-treatment resulted in higher porosity in specimens S2 and S3. Subsequently, the dynamic modulus increased monotonically by $\sim 3$ GPa at the end of the test. The causes leading to this increase may be sundry. Further cement hydration and so strength development may be plausible causes. Likewise, the increasing internal moisture content over the test duration may also lead to an increase in the dynamic modulus [36]. In contrast, the values of dynamic Poisson's ratio remained constant; these results are not shown for brevity. For reference, the average Poisson's for the three samples was $\sim 0.2$ [26]. The values of $Q$ corresponding to the reference sample were significantly higher than those of the heat-treated samples. Also, despite the scatter of the data, the values of $Q$ slightly increased (say, the attenuation decreased) in all cases. Figures $5 \mathrm{c}$ and $5 \mathrm{~d}$ show the evolution of the nonlinear hysteretic parameters $\alpha_{f}$ and $\alpha_{Q}$. These values are in good agreement with previously reported values for concrete [37]. Likewise, the ratio between both $\alpha_{f} / \alpha_{Q}$ equals to $\sim 0.3$. As for other solids this ratio was reported to be lower than 1 [33]. However, no meaningful trend was observed. Overall, no damage can be inferred from the evolutions of dynamic elastic modulus, $Q$, or the hysteretic parameters $\alpha_{f}$ and $\alpha_{Q}$.

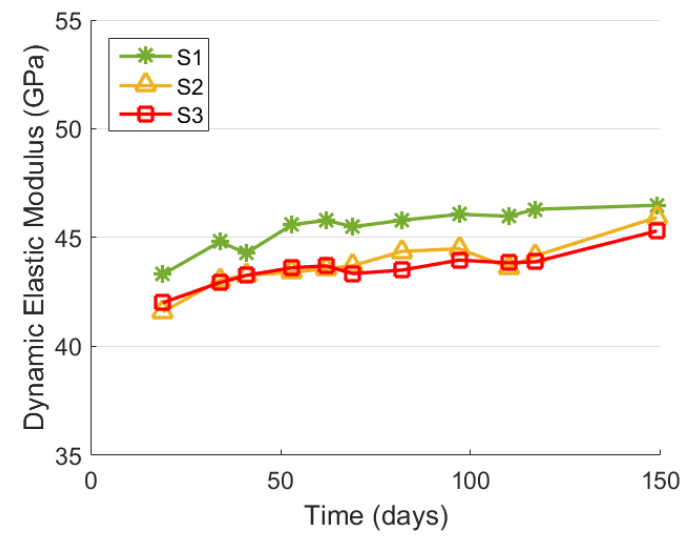

a)

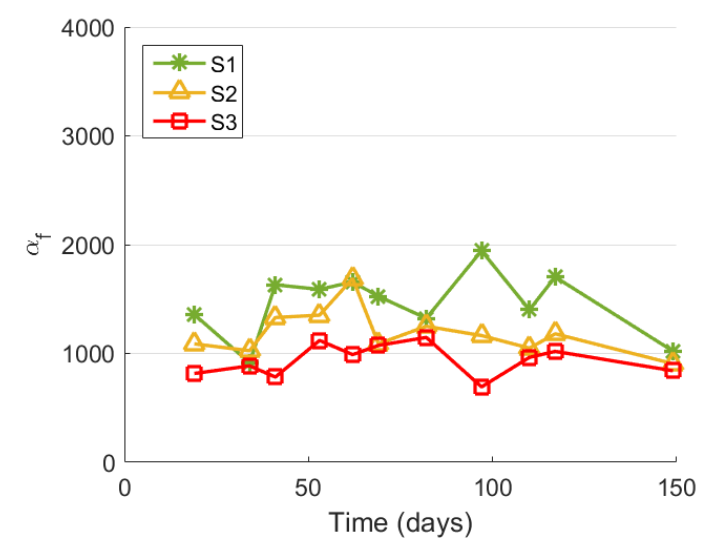

c)

Figure 4. Evolution of a) Dynamic modulus (measurement uncertainty of $\pm 0.5 G P a)$, b) Quality factor, $c$ ) nonlinear parameter $\alpha_{f}$ (measurement uncertainty of \pm 500$)$ and $\left.d\right)$ nonlinear parameter

$\alpha_{Q}$

Figures $6 \mathrm{a}$ and $6 \mathrm{~b}$ show two SEM micrographs taken on sample S3. A small pore (Figure 6a), and a paste-aggregate interface (Figure 6b) are shown; sulfate-bearing crystals were identified in both instances. However, the sole observation of ettringite at the microscopic scale does not render an explanation for the observed results. Figures $7 \mathrm{a}$ and $7 \mathrm{~b}$ compares the optical microscope images under normal- and UV-light for samples S1 and S3. Overall, the microscope images did not show qualitative differences between both samples. A similar extent of cracking was observed.

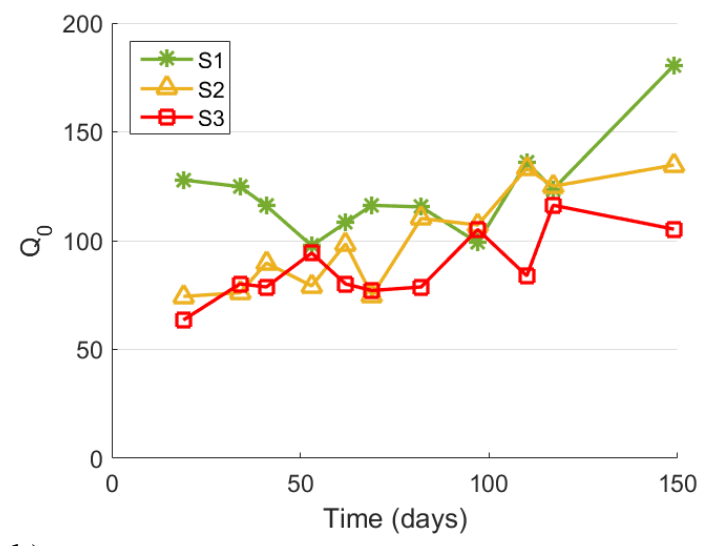

b)

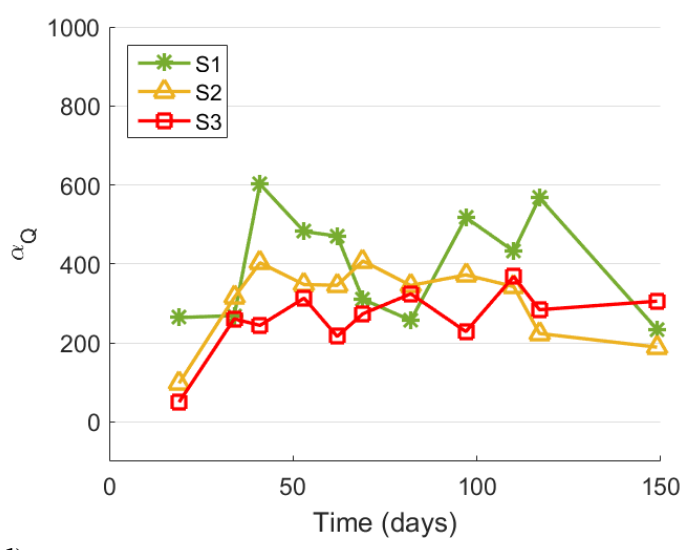

d)

(1) 
F. Ouvrier-Buffet et al., Linear and nonlinear resonant ultrasonic techniques applied to assess delayed ettringite formation on concrete samples, Construction and Building Materials (2021) - https://doi.org/10.1016/j.conbuildmat.2020.121545

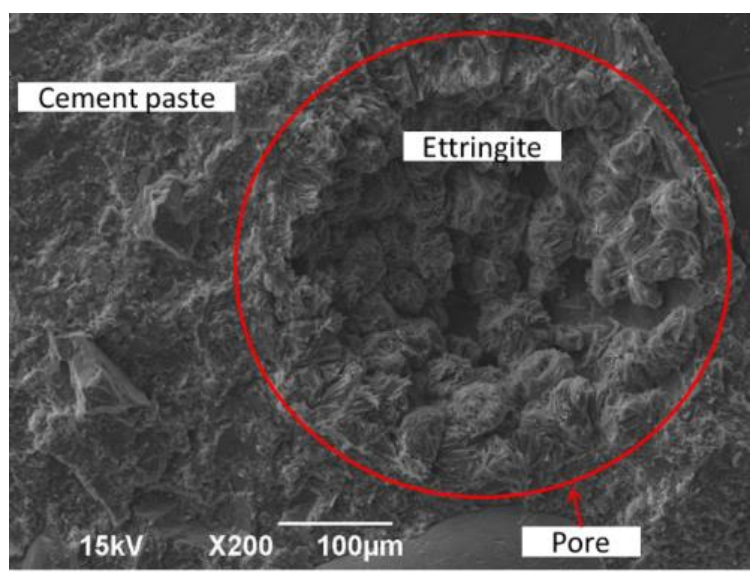

a)

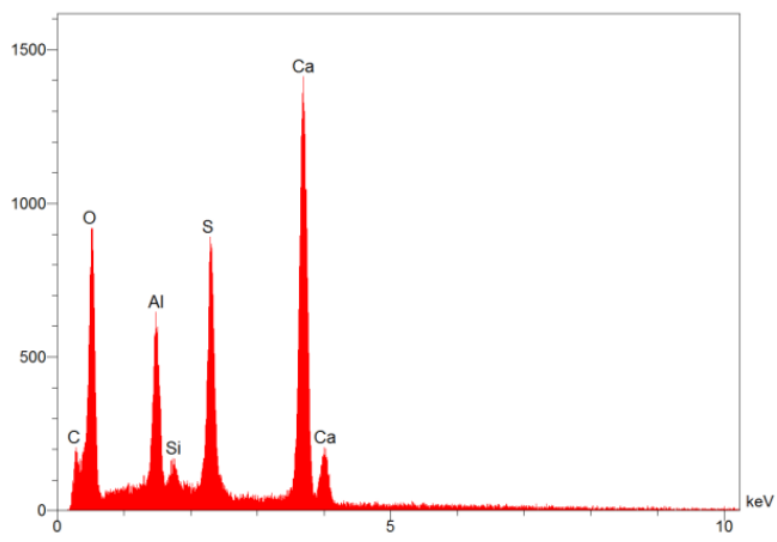

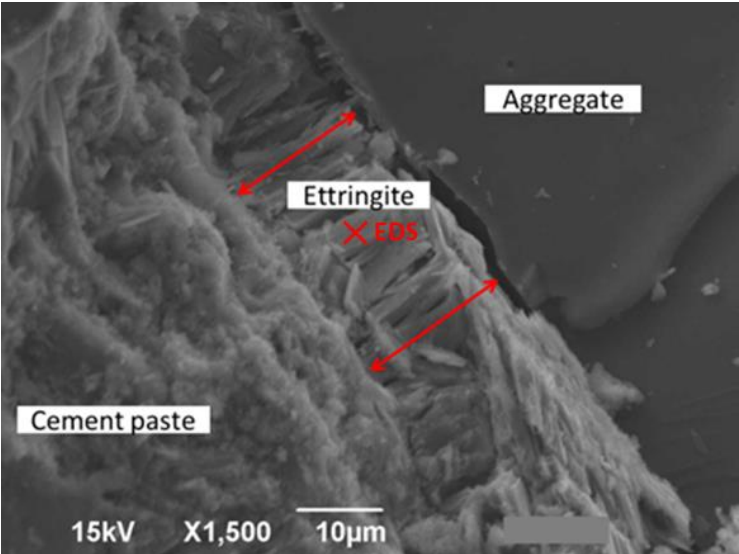

b)

c)

Figure 5: SEM images ettringite crystals are shown a) in a pore and b) at paste-aggregate interface. c) EDS carried out at the point marked by the red cross in image b).
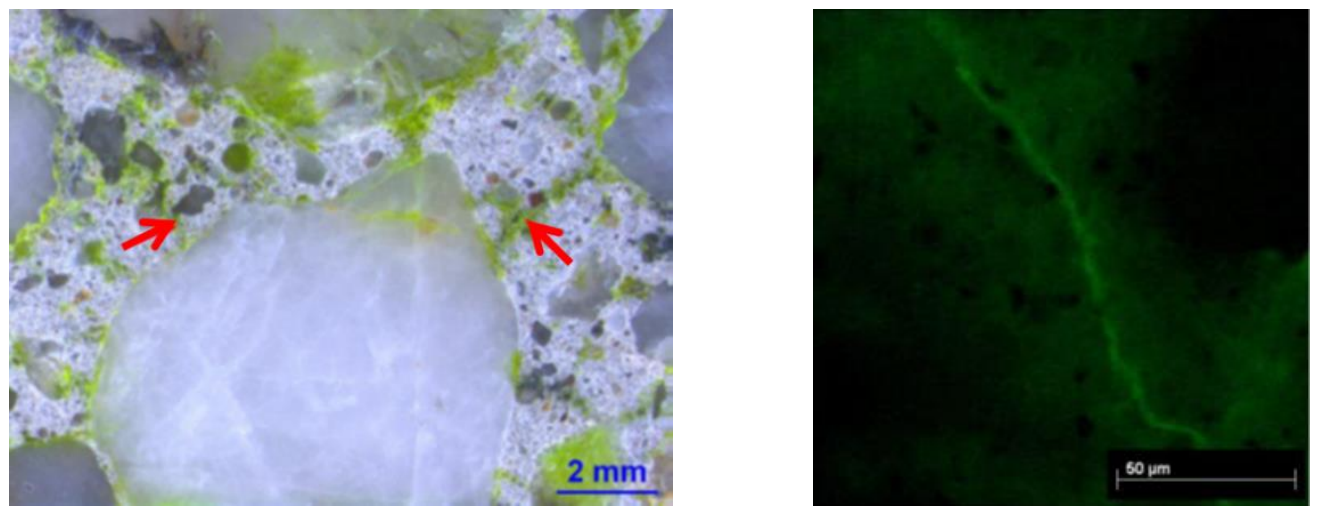
F. Ouvrier-Buffet et al., Linear and nonlinear resonant ultrasonic techniques applied to assess delayed ettringite formation on concrete samples, Construction and Building Materials (2021) - https://doi.org/10.1016/j.conbuildmat.2020.121545
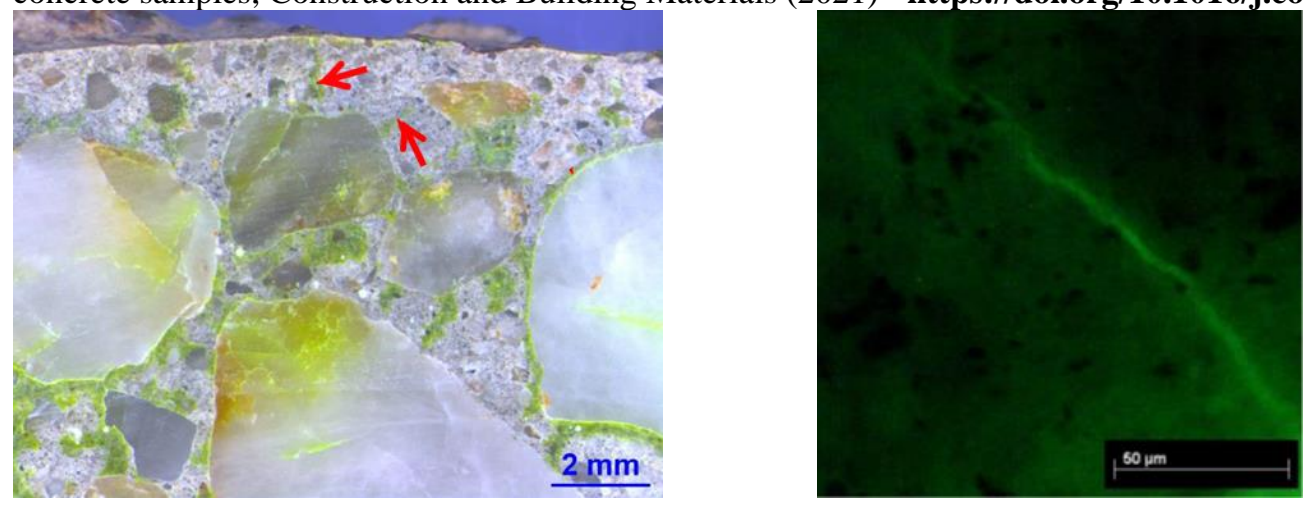

Figure 6: Optical microscopy images under normal- and UV-light for sample S1 a) and b), and for sample $S 3$ c) and d); cracks are indicated with red arrows.

\section{Discussion and conclusions}

This study evaluated the DEF susceptibility at early ages of a concrete mix whose constituents (ciment type and aggregates) are commonly used in nuclear facilities. The tests were realized on three prismatic specimens measuring $7 \times 7 \times 28 \mathrm{~cm}^{3}$. The different curing and aging conditions allowed us to attain different expansion extents because of DEF. At the end of the tests, the measured expansions were $0.02 \%$ for control specimen, $0.06 \%$ and $0.21 \%$ for pathological specimens. The changes were further informed by several nondestructive means: cumulative AE hits, and by linear and nonlinear resonance tests. The following observations are drawn:

- The AE technique attested the occurrence of more AE hits on the heat-treated specimen than in the control specimen S1. The total number of hits for heat-treated specimens with regard to those obtained for the control sample are low when compared to other studies [31]. Probably, because mechanical damage was not effectively generated. Moreover, whether these AE hits were originated by DEF or other causes could not be differentiated. The identification of signal features that could uniquely be attributed to DEF remains a challenge which does not allow a physical quantification of the mechanical properties. Therefore, the sole observation of AE activity may lead to misleading conclusions about development of DEF and have to be complemented with other measurements.

- The mass, dynamic modulus of elasticity, and $Q$ increased over the test duration for all the specimens. The developpement of DEF in pathological specimens did not lead to specific evolution of these parameters compared to control specimen. The increase of mass suggests that the internal moisture of the samples might increase. The absorption of moisture may contribute to an increase in the dynamic modulus in concrete which is attributed to a rise in the capillary pressure [36,38]. However, the sole effect of internal moisture is expected to be accompanied by a reduction of $Q$ (thus, increased attenuation) [36]. A trade-off between internal moisture absorption and desiccation because of further cement hydration, and thus strength development, are likely causes leading to an increase of all three parameters (dynamic modulus, $Q$, and mass).

- The nonlinear hysteretic parameters $\alpha_{f}$ and $\alpha_{Q}$ appeared to be constant over the test duration for all the specimens. The formation of delayed ettringite on the two pathological free boundaries specimens did not produce meaningful changes of the nonlinear paremeters as it can be observed for another swelling pathology [14]. Recall that the relative variation of the nonlinear hysteretic parameters upon damage generation is commonly several orders of magnitude higher than linear ones [18]. SEM micrographs and mircrocraking analyses carried out on the most affected sample provided some elements of response: ettringite is mainly observed at paste-aggregate interface and did not produce mechanical damage despite concrete expansion. Thus the stability of the nonlinear paremeters (which are commonly very sensitive to internal concrete bonds) combined with microscopy analyses allow to formulate the following hypothesis for this concrete mix and these DEF aging conditions: ettringite crystals could first fill the ITZ without weaken aggregate-cement paste bonds and therefore the nonlinearity.

Overall, the results indicate that in spite of the attained expansions ( $0.21 \%$ over 150 days for the most affected sample) mechanical damage was not produced. The results obtained in this study are in good agreement with previously reported values on concrete samples and in which very similar heat-treatment protocols were applied [39]. A continuous increase of dynamic modulus was observed upon the development of DEF up to expansions of $\sim 0.20 \%$ for many of the concrete types studied in [39]. We further substantiated the absence of mechanical damage through attenuation and nonlinear hysteretic parameters. However, even if such expansions did not generate damage under unrestrained conditions (often associated with low expansion kinetics) at the sample scale, the behavior may be 
F. Ouvrier-Buffet et al., Linear and nonlinear resonant ultrasonic techniques applied to assess delayed ettringite formation on concrete samples, Construction and Building Materials (2021) - https://doi.org/10.1016/j.conbuildmat.2020.121545

different under loading. To this respect, the recent works of Thiebaut et al. [40] on the effects of stress on DEF may be relevant and should be generalized to better understand the degradation mechanisms owed to swelling pathologies.

\section{Acknowledgments}

This work was carried out as part of the ODOBA project (Observatoire de la Durabilité des Ouvrages en Béton Armé) led by the French technical safety organization (Institut de Radioprotection et de Sureté Nucléaire - IRSN). 
F. Ouvrier-Buffet et al., Linear and nonlinear resonant ultrasonic techniques applied to assess delayed ettringite formation on concrete samples, Construction and Building Materials (2021) - https://doi.org/10.1016/j.conbuildmat.2020.121545

\section{References}

[1] M. Collepardi, A state-of-the-art review on delayed ettringite attack on concrete, Cem. Concr. Compos. (2003).

[2] S. Mindess, J.F. Young, D. Darwin, Concrete, Prentice Hall, 2003.

[3] H.F.W. Taylor, C. Famy, K.L. Scrivener, Delayed ettringite formation, Cem. Concr. Res. 31 (2001) 683-693.

[4] A. Campos, C.M. López, A. Blanco, A. Aguado, Effects of an internal sulfate attack and an alkali-aggregate reaction in a concrete dam, Constr. Build. Mater. 166 (2018) 668-683. doi:10.1016/j.conbuildmat.2018.01.180.

[5] M. Thomas, K. Folliard, T. Drimalas, T. Ramlochan, Diagnosing delayed ettringite formation in concrete structures, Cem. Concr. Res. 38 (2008) 841-847. doi:10.1016/j.cemconres.2008.01.003.

[6] V. Penttala, Causes and mechanisms of deterioration in reinforced concrete, in: Fail. Distress Repair Concr. Struct., Elsevier Ltd, 2009: pp. 3-31. doi:10.1533/9781845697037.1.3.

[7] Autorité de Sûreté Nucléaire, Contrôle des installations nucléaires de base CNPE de Chooz. Ref: CODEPCHA-2016-045635, 2016. https://www.asn.fr/content/download/107768/834634/version/1/file/INSSN-CHA2016-0102.pdf.

[8] Z. Zhang, J. Olek, S. Diamond, Studies on delayed ettringite formation in heat-cured mortars: II. Characteristics of cement that may be susceptible to DEF, Cem. Concr. Res. 32 (2002) 1737-1742. doi:10.1016/S0008-8846(02)00894-3.

[9] M. Santhanam, M.D. Cohen, J. Olek, Mechanism of sulfate attack: A fresh look, Cem. Concr. Res. 32 (2002) 915-921. doi:10.1016/S0008-8846(02)00724-X.

[10] A. Neville, The confused world of sulfate attack on concrete, Cem. Concr. Res. 34 (2004) 1275-1296. doi:10.1016/j.cemconres.2004.04.004.

[11] M.D. Cohen, B. Mather, Sulfate Attack on Concrete - Research Needs, ACI Mater. J. (1991) 62-69.

[12] J. Chen, A.R. Jayapalan, J.Y. Kim, K.E. Kurtis, L.J. Jacobs, Rapid evaluation of alkali-silica reactivity of aggregates using a nonlinear resonance spectroscopy technique, Cem. Concr. Res. 40 (2010) 914-923. doi:10.1016/j.cemconres.2010.01.003.

[13] K.J. Leśnicki, J.-Y. Kim, K.E. Kurtis, L.J. Jacobs, Assessment of alkali-silica reaction damage through quantification of concrete nonlinearity, Mater. Struct. 46 (2012) 497-509. doi:10.1617/s11527-012-9942-y.

[14] Y. Boukari, D. Bulteel, P. Rivard, N.E. Abriak, Combining nonlinear acoustics and physico-chemical analysis of aggregates to improve alkali-silica reaction monitoring, Cem. Concr. Res. 67 (2015) 44-51. doi:10.1016/j.cemconres.2014.08.005.

[15] J.N. Eiras, T. Kundu, J.S. Popovics, J. Monzó, L. Soriano, J. Payá, Evaluation of frost damage in cement-based materials by a nonlinear elastic wave technique, in: T. Kundu (Ed.), Proc. SPIE Conf., 2014: p. 90641G. doi:10.1117/12.2035951.

[16] J. Jin, M.G. Moreno, J. Riviere, P. Shokouhi, Impact-Based Nonlinear Acoustic Testing for Characterizing Distributed Damage in Concrete, J. Nondestruct. Eval. 36 (2017). doi:10.1007/s10921-017-0428-2.

[17] R. Rashetnia, F. Ghasemzadeh, M. Pour-Ghaz, The Consequences of Material Nonlinearity on the Axisymmetric Flexural Vibration Measurements for Estimating the Dynamic Elastic Modulus of Damaged Cement Based Materials, J. Adv. Concr. Technol. 14 (2016) 287-298. doi:10.3151/jact.14.287.

[18] C. Payan, V. Garnier, J. Moysan, P. a Johnson, Applying nonlinear resonant ultrasound spectroscopy to improving thermal damage assessment in concrete., J. Acoust. Soc. Am. 121 (2007) EL125-L130. doi:10.1121/1.2710745.

[19] S.-J. Park, H.J. Yim, H.-G. Kwak, Effects of post-fire curing conditions on the restoration of material properties of fire-damaged concrete, Constr. Build. Mater. 99 (2015) 90-98. doi:10.1016/j.conbuildmat.2015.09.015.

[20] F. Bouchaala, C. Payan, V. Garnier, J.P. Balayssac, Carbonation assessment in concrete by nonlinear ultrasound, Cem. Concr. Res. 41 (2011) 557-559. doi:10.1016/j.cemconres.2011.02.006.

[21] J.N. Eiras, T. Kundu, J.S. Popovics, J. Monzó, M. V. Borrachero, J. Payá, Effect of carbonation on the linear and nonlinear dynamic, Opt. Eng. 55 (2016) 01104(1)-01104(8).

[22] M. Rashidi, A. Paul, J.Y. Kim, L.J. Jacobs, K.E. Kurtis, Insights into delayed ettringite formation damage 
F. Ouvrier-Buffet et al., Linear and nonlinear resonant ultrasonic techniques applied to assess delayed ettringite formation on concrete samples, Construction and Building Materials (2021) - https://doi.org/10.1016/j.conbuildmat.2020.121545 through acoustic nonlinearity, Cem. Concr. Res. 95 (2017) 1-8. doi:10.1016/j.cemconres.2017.02.004.

[23] K.E. Van Den Abeele, A. Sutin, J. Carmeliet, P. a. Johnson, Micro-damage diagnostics using nonlinear elastic wave spectroscopy (NEWS), NDT E Int. 34 (2001) 239-248. doi:10.1016/S0963-8695(00)00064-5.

[24] D. Pasqualini, K. Heitmann, J.A. Tencate, S. Habib, D. Higdon, P.A. Johnson, Nonequilibrium and nonlinear dynamics in Berea and Fontainebleau sandstones : Low-strain regime, J. Geophys. Res. 112 (2007) 1-16. doi:10.1029/2006JB004264.

[25] D. Damidot, Thermodynamic investigation of the $\mathrm{CaO}-\mathrm{AI} 203-\mathrm{CaSO} 4-\mathrm{H} 20$ system at $50^{\circ} \mathrm{C}$ and $85^{\circ} \mathrm{C}, \mathrm{Cem}$. Concr. Res. 22 (1992) 1179-1191.

[26] F. Ouvrier-Buffet, Apport aux contrôles non destructifs ultrasonores pour la détection des pathologies de gonflement interne du béton, Aix Marseille Université, 2019.

[27] A. Pavoine, L. Divet, S. Fenouillet, A concrete performance test for delayed ettringite formation: Part II validation, Cem. Concr. Res. 36 (2006) 2144-2151. doi:10.1016/j.cemconres.2006.09.010.

[28] S.O. Ekolu, M.D.A. Thomas, R.D. Hooton, Dual effectiveness of lithium salt in controlling both delayed ettringite formation and ASR in concretes, Cem. Concr. Res. 37 (2007) 942-947. doi:10.1016/j.cemconres.2007.01.014.

[29] C.U. Grosse, M. Ohtsu, Acoustic Emission Testing. Basic for Research-Applications in Civil Engineering, 2008. doi:10.1017/CBO9781107415324.004.

[30] T. Fowler, J. Blessing, P. Conlisk, T. Swanson, The MONPAC system, J. Acoust. Emiss. 8 (1989) 1-8.

[31] M. Abdelrahman, M.K. ElBatanouny, P. Ziehl, J. Fasl, C.J. Larosche, J. Fraczek, Classification of alkali-silica reaction damage using acoustic emission: A proof-of-concept study, Constr. Build. Mater. 95 (2015) $406-413$. doi:10.1016/j.conbuildmat.2015.07.093.

[32] ASTM C215-14, Standard Test Method for Fundamental Transverse, Longitudinal, and Torsional Resonant Frequencies of Concrete, (2014) 1-9.

[33] P. Johnson, A. Sutin, Slow dynamics and anomalous nonlinear fast dynamics in diverse solids., J. Acoust. Soc. Am. 117 (2005) 124-130. doi:10.1121/1.1823351.

[34] C. Payan, T.J. Ulrich, P.Y. Le Bas, T. Saleh, M. Guimaraes, Quantitative linear and nonlinear resonance inspection techniques and analysis for material characterization: Application to concrete thermal damage., J. Acoust. Soc. Am. 136 (2014) 537-547. doi:10.1121/1.4887451.

[35] LCPC, Réactivité d'un béton vis-à-vis d'une réaction sulfatique interne : Essai de performance, Laboratoire Central des Ponts et Chaussées, 2007.

[36] J.N. Eiras, J.S. Popovics, M.V. Borrachero, J. Monzó, J. Payá, The effects of moisture and micro-structural modifications in drying mortars on vibration-based NDT methods, Constr. Build. Mater. 94 (2015) 565-571. doi:10.1016/j.conbuildmat.2015.07.078.

[37] C. Payan, T.J. Ulrich, P.Y. Le Bas, T. Saleh, M. Guimaraes, Quantitative linear and nonlinear resonance inspection techniques and analysis for material characterization: Application to concrete thermal damage., J. Acoust. Soc. Am. 136 (2014) 537. doi:10.1121/1.4887451.

[38] L.O. Yaman, N. Hearn, H.M.I. Aktan, Active and non-active porosity in concrete Part I : Experimental evidence, Mater. Struct. 35 (2002) 102-109.

[39] X. Brunetaud, L. Divet, D. Damidot, Impact of unrestrained Delayed Ettringite Formation-induced expansion on concrete mechanical properties, Cem. Concr. Res. 38 (2008) 1343-1348. doi:10.1016/j.cemconres.2008.05.005.

[40] Y. Thiebaut, S. Multon, A. Sellier, L. Lacarrière, L. Boutillon, D. Belili, L. Linger, F. Cussigh, S. Hadji, Effects of stress on concrete expansion due to delayed ettringite formation, Constr. Build. Mater. 183 (2018) 626-641. doi:10.1016/j.conbuildmat.2018.06.172. 